\title{
Ultrasonic Study of Binary Liquid Mixture of n-Hexane and Acetic Acid
}

\author{
H.K Semwal ${ }^{1}$, Manish Uniyal ${ }^{2}$, S.C Bhatt ${ }^{3}$ \\ Department of physics, HNB Garhwal University Srinagar Garhwal, Uttarakhand-246174, India
}

\begin{abstract}
The velocity of ultrasonic wave in binary liquid mixtures of n-hexane and acetic acid has been measured at 1,2,3,4,5,6 and 7 MHz frequencies at room temperature with the help of ultrasonic interferometer. Isentropic compressibility (ks), Acoustic impedance (Z) and Relaxation time $(T)$ have been calculated for the whole composition range for these binary mixtures.
\end{abstract}

Keywords: Ultrasonic waves, Isentropic compressibility, Acoustic impedance, Relaxation time.

\section{Introduction}

The propagation of ultrasonic waves in any liquid mixture has become a fundamental test to investigate its properties. Ultrasonic wavelength measurement has been adequately employed for to understand the nature of molecular interaction in pure liquids, binary and ternary mixtures and the Ionic interactions in electrolytic solutions.

The study of properties of the liquid mixture of polar as well as non-polar components finds application in various fields like medical, industrial and technological processes etc., as such liquid mixtures provide a wide range solutions with appropriate properties [1-3]. When acoustic waves are propagated through a liquid, dissipation of acoustic energy that is associated with changes in the molecular structure of the medium results from the finite time that is required for these changes to take place.

Miscibility of ethylene-vinyl acetate with polystyrene was studied in toluene solution using viscometer and ultrasound analysis [4]. Ultrasonic velocity and density for binary liquid mixtures of $\mathrm{N}, \mathrm{N}$ - dimethyl formamide with methoxyl ethanol,2-ethoxy ethanol and 2-butoxyl ethanol have been determined at $308.5 \mathrm{k}$ over the entire mole fraction range and different acoustic parameters have been calculated [5].Velocity of ultrasonic waves in different liquid medium have been measured [6-7] at room temperature and adiabatic compressibility, acoustic impedance and relaxation time have been calculated for these liquids.

Measurement of ultrasonic velocity [8-11] has been adequately employed in understanding the molecular interactions in pure, binary, and higher order multicomponent liquid mixtures. The propagation of ultrasonic velocity in a medium is a thermodynamic property and has come to be recognized as a very specific and unique tool for predicting and estimating various physio-chemical properties of the systems under consideration [12] .

Many researchers have studied the acoustical behavior of liquids and liquid system, true information is used to study the nature of interaction and application of these systems. Ultrasonic velocities have been measured in binary organic liquid mixtures using a variable frequency fixed path ultrasonic interferometer.
In the present investigations we have measured Ultrasonic velocity in binary liquid mixture of $n$-hexane and acetic acid at room temperature with the help of ultrasonic interferometer at different frequencies ranging from $1 \mathrm{MHz}$ to $7 \mathrm{MHz}$ and calculated isentropic compressibility, Acoustic impedance and Relaxation time for this mixed system.

\section{Experimental Measurement}

The Ultrasonic interferometer is a simple and direct device to determine the ultrasonic velocity in liquid. The principle used in the measurement of ultrasonic velocity is based on the determination of wavelength in the liquid mixture. The ultrasonic waves of known frequency are produced by quartz crystal fixed at the bottom of the measuring liquid cell.

The measuring cell is connected to the output terminal of the high frequency generator through the spherical cable. A mobile metallic plate kept parallel to the quartz crystal reflects these waves. If the separation between these two plates is exactly a whole multiple of the sound wavelength, standing waves are formed in the medium. These acoustic resonances gives rise to an electrical reaction on the generator, driving the quartz crystal and anode current of the generator become maximum.

The high frequency generator is designed to exited the quartz crystal fixed at the bottom of the measuring cell. If the distance is now increased or decreased and the variation is exactly one half the wavelengths or multiple of it, anode current become maximum. A number of maxima reading of anode current are passed and their number $n$ is counted. The total distance (d) moved by the micrometer gives the value of the wavelength as-

$$
\mathrm{D}=\mathrm{n} \lambda / 2
$$

The least count of the micrometer used for measuring the wavelength is $.001 \mathrm{~mm}$. Now the ultrasonic velocity can be obtained if the wavelength is known.

\section{Calculation}

The ultrasonic velocity measurements are extensively used to study physio-chemical behavior of liquids with the help of measured ultrasonic velocity and density, using following formula. Acoustic parameters like Isentropic compressibility, Acoustic impedance and Relaxation-time 


\section{International Journal of Science and Research (IJSR) \\ ISSN (Online): 2319-7064 \\ Index Copernicus Value (2013): 6.14 | Impact Factor (2014): 5.611}

have been calculated and results are tabulated, plotted and discussed.

1) Ultrasonic velocity (u) was calculated from the ultrasonic wavelength. $\mathrm{U}=\mathrm{n} \lambda$

2) Isentropic compressibility $\mathrm{Ks}=\mathrm{U}^{-2} \rho^{-1}$

3) Acoustic impedance $\mathrm{Z}=\rho \mathrm{XU}$

Table 1.1: Ultrasonic velocity in Binary liquid mixture of $n$-hexane and acetic acid at different frequencies \& composition:

\begin{tabular}{|ll|c|c|c|c|c|c|c|c|}
\hline \multicolumn{2}{|c|}{$\begin{array}{c}\text { Binary liquid mixture } \\
\text { composition (volume) }\end{array}$} & Density & \multicolumn{5}{c|}{ Ultrasonic velocity(m/s) at different frequencies } \\
\hline n-Hexane\% & Acetic acid\% & $(\mathrm{g} / \mathrm{cc})$ & $1 \mathrm{MHz}$ & $2 \mathrm{MHz}$ & $3 \mathrm{MHz}$ & $4 \mathrm{MHz}$ & $5 \mathrm{MHz}$ & $6 \mathrm{MHz}$ & $7 \mathrm{MHz}$ \\
\hline 0 & 100 & .997 & 4914 & 4917 & 4919 & 4920 & 4921 & 4922 & 4923 \\
\hline 20 & 80 & .606 & 5718 & 5629 & 5630 & 5632 & 5633 & 5635 & 5636 \\
\hline 40 & 60 & .696 & 5758 & 5187 & 5189 & 5190 & 5189 & 5190 & 5192 \\
\hline 60 & 40 & .664 & 6914 & 5735 & 5735 & 5736 & 5737 & 5737 & 5738 \\
\hline 80 & 20 & .617 & 6967 & 6628 & 6629 & 6630 & 6631 & 6631 & 6632 \\
\hline 100 & 0 & .586 & 6916 & 7318 & 7319 & 7320 & 7321 & 7321 & 7322 \\
\hline
\end{tabular}

Table 1.2: Isentropic compressibility of Binary liquid mixture of n-hexane and acetic acid at different frequencies \& composition

\begin{tabular}{|l|l|l|l|l|l|l|l|l|}
\hline $\begin{array}{l}\text { Binary liquid mixture } \\
\text { composition (volume) }\end{array}$ & \multicolumn{3}{|l}{$\begin{array}{l}\text { Isentropic } \\
\text { frequencies }\left(\mathrm{x} 10-{ }^{3}\right)\end{array}$} \\
\hline $\mathrm{n}$-Hexane\% & Acetic acid\% & $1 \mathrm{MHz}$ & $2 \mathrm{MHz}$ & $3 \mathrm{MHz}$ & $\begin{array}{l}4 \mathrm{MH} \\
\mathrm{z}\end{array}$ & $\begin{array}{l}5 \mathrm{MH} \\
\mathrm{z}\end{array}$ & $6 \mathrm{MHz}$ & $7 \mathrm{MHz}$ \\
\hline 0 & 100 & .865 & .843 & .825 & .807 & .795 & .785 & .777 \\
\hline 20 & 80 & .136 & .134 & .133 & .132 & .131 & .1299 & .129 \\
\hline 40 & 60 & 1.178 & 1.164 & 1.151 & 1.141 & 1.133 & 1.123 & 1.115 \\
\hline 60 & 40 & 1.23 & 1.21 & 1.19 & 1.18 & 1.17 & 1.169 & 1.162 \\
\hline 80 & 20 & 1.317 & 1.298 & 1.285 & 1.269 & 1.262 & 1.249 & 1.242 \\
\hline 100 & 0 & 1.092 & 1.075 & 1.059 & 1.045 & 1.031 & 1.024 & 1.017 \\
\hline
\end{tabular}

Table 1.3: Acoustic impedence of Binary liquid mixture of $n$-hexane and acetic acid at different frequencies \& composition

\begin{tabular}{|l|l|l|l|l|l|l|l|c|}
\hline \multicolumn{2}{|l|}{$\begin{array}{l}\text { Binary liquid mixture } \\
\text { composition (volume) }\end{array}$} & \multicolumn{6}{|l|}{ Acoustic impedence $\left(\mathrm{Kgm}^{-2} \mathrm{~s}^{-1}\right)$ at different frequencies } \\
\hline n-Hexane $\%$ & Acetic acid\% & $1 \mathrm{MHz}$ & $2 \mathrm{MHz}$ & $3 \mathrm{MHz}$ & $4 \mathrm{MHz}$ & $5 \mathrm{MHz}$ & $6 \mathrm{MHz}$ & $7 \mathrm{MHz}$ \\
\hline 0 & 100 & 1.085 & 1.099 & 1.112 & 1.124 & 1.132 & 1.139 & 1.145 \\
\hline 20 & 80 & .666 & .671 & .6744 & .6775 & .6799 & .6829 & .6853 \\
\hline 40 & 60 & .768 & .773 & .777 & .780 & .7836 & .7871 & .7899 \\
\hline 60 & 40 & .734 & .740 & .744 & .7476 & .7509 & .7536 & .7556 \\
\hline 80 & 20 & .684 & .689 & .692 & .697 & .699 & .702 & .704 \\
\hline 100 & 0 & .792 & .798 & .804 & .810 & .815 & .818 & .821 \\
\hline
\end{tabular}

Table 1.4: Relaxation time of Binary liquid mixture of n-hexane and acetic acid at different frequencies \& composition

\begin{tabular}{|lc|c|c|c|c|c|c|c|}
\hline $\begin{array}{c}\text { Binary liquid mixture } \\
\text { composition (volume) }\end{array}$ & \multicolumn{7}{|c|}{ Relaxation time(second) at different frequencies } \\
\hline n-Hexane\% & Acetic acid\% & $1 \mathrm{MHz}$ & $2 \mathrm{MHz}$ & $3 \mathrm{MHz}$ & $4 \mathrm{MHz}$ & $5 \mathrm{MHz}$ & $6 \mathrm{MHz}$ & $7 \mathrm{MHz}$ \\
\hline 0 & 100 & .152 & .148 & .105 & .142 & .140 & .138 & .136 \\
\hline 20 & 80 & .227 & .224 & .222 & .220 & .218 & .216 & .215 \\
\hline 40 & 60 & .183 & .181 & .179 & .178 & .176 & .175 & .173 \\
\hline 60 & 40 & .167 & .164 & .162 & .161 & .160 & .158 & .158 \\
\hline 80 & 20 & .156 & .154 & .152 & .151 & .149 & .148 & .147 \\
\hline 100 & 0 & .139 & .136 & .134 & .132 & .131 & .130 & .129 \\
\hline
\end{tabular}

Volume 4 Issue 12, December 2015 www.ijsr.net 
International Journal of Science and Research (IJSR)

ISSN (Online): 2319-7064

Index Copernicus Value (2013): 6.14 | Impact Factor (2014): 5.611

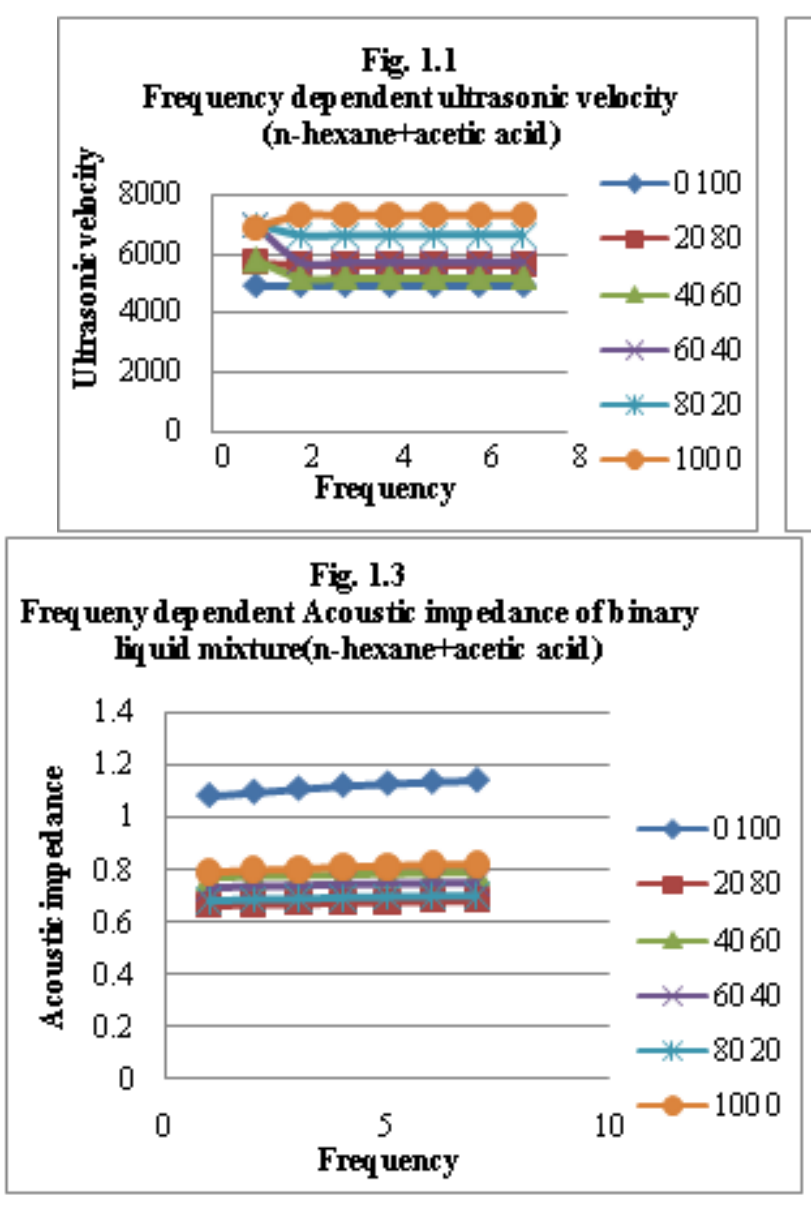

\section{Result and Discussion}

Ultrasonic velocity has been measured by variable path interferometer at different frequencies from $1 \mathrm{MHZ}$ to $7 \mathrm{MHZ}$ at room temperature in Binary liquid mixture of n-hexane and acetic acid.

Ultrasonic velocity in binary liquid mixtures (n-hexane + acetic acid) presented in table-1.1 and fig1.1. From the table and figure it is observed that in binary liquid mixture ultrasonic velocity increases with increasing frequency, while with increasing composition of n-hexane in liquid mixture the ultrasonic velocity also increases.

Isentropic compressibility of binary liquid mixture have been calculated using formula $\mathrm{Ks}=\mathrm{U}^{-2} \rho^{-1}$ and acoustic impedance is calculated by the equation $Z=\rho x U$. From the table-1.2 and figure-1.2, the isentropic compressibility of binary liquid mixture is decreasing with increasing frequency while increasing the composition of n-hexane in liquid mixture the isentropic compressibility is decreasing.

In binary liquid mixture table-1.3 and figure-1.3 shows that acoustic impedance slightly increases with increasing frequency while increasing the composition of n-hexane in liquid mixture the acoustic impedance also increases.

Relaxation time is also calculated using formula $\mathrm{T}=4 \mathrm{\eta} / 3 \rho \mathrm{U}^{2}$. The values of relaxation time are also shown in table-1.4 and figure-1.4. It is observed that relaxation time in binary liquid mixture (n-hexane + acetic acid) slightly decreases with increasing frequency while increasing the
Fig. 1.2

Frequency dependent isentropic compressibility (n-hexane+acetic acid)

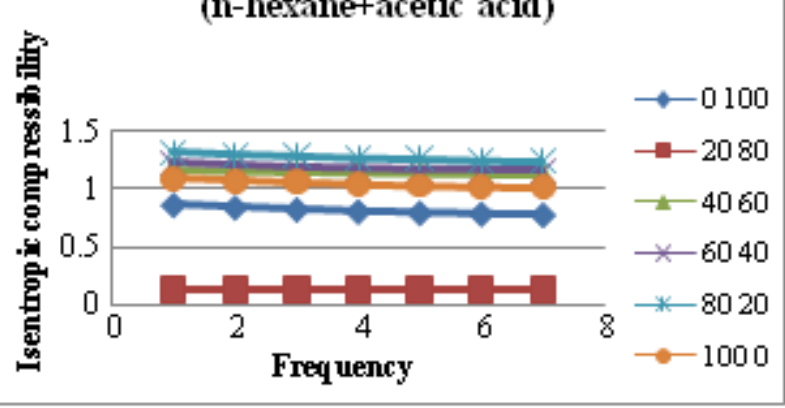

Fig. 1.4

Frequeny dependent Rebation time(n-hexanetacetic acid)

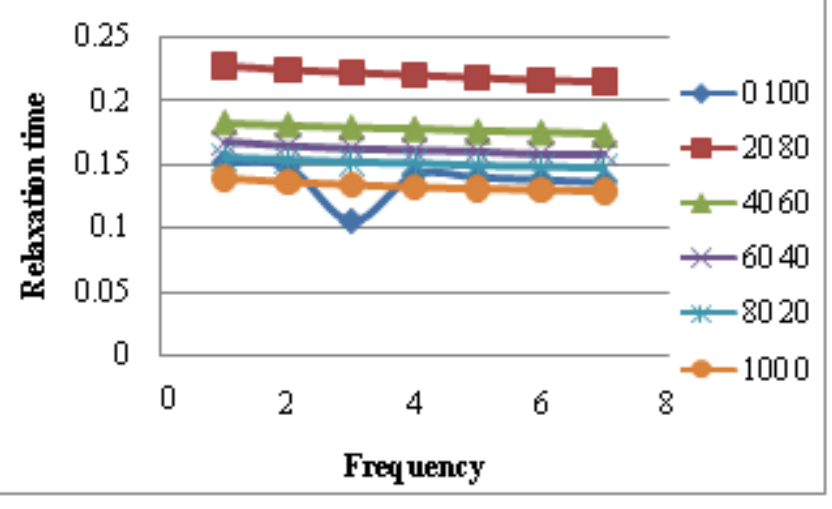

composition of $\mathrm{n}$-hexane in liquid mixture the relaxation time decreases.

\section{Conclusion}

The variation of ultrasonic velocity, Isentropic compressibility, Acoustic impedance and Relaxation time for different compositions of binary liquid mixtures nHexane and acetic acid at different frequencies at room temperature have been shown in table 1.1 to 1.4 \& respectively and plotted in figures 1.1 to 1.4 respectively. From table and figure it is observed that ultrasonic velocity slightly increases with increase in frequency for liquid mixture. Isentropic compressibility, acoustic impedance and relaxation time show a transition type behavior with increasing percentage of acetic acid, their values depend upon the composition ratio of carbon and hydrogen atom in binary liquid mixture.

\section{References}

[1] K.Subba Rao, B.Ramchandra Rao, "Ultrasonic studies in some organic liquid mixtures", J. Industr. Res. , 18B,223,1959.

[2] N.Kannappan and V.Rajendran,"Acoustic parameter of some ternary liquid mixtures" ,Ind. J. Pure \& App.Phy. ,30,240, 1992.

[3] V.R Murthy,K.V Siva kumar,R.N.V Ranga Reddy \& Y.Narasimha Murthy, "Ultrasonic study of natural oils and fats plant origin”, Cryst.Res.Tech.,28,723,1993.

[4] N.Somanathan,V.Arumugan and R.Balakrishanan, "Ultrasonic study of ethylene-venyl acetate with

\section{Volume 4 Issue 12, December 2015}




\section{International Journal of Science and Research (IJSR) \\ ISSN (Online): 2319-7064}

Index Copernicus Value (2013): 6.14 | Impact Factor (2014): 5.611

polysterene blend solution", J. Pure. Appl. Ultrason., 23, 37, 2001.

[5] S.B.Alisha,M.C.S. Subha and K.C.Rao, "Ultrasonic velocity and density studies in binary liquid mixtures of N,N-dimethyl- formamide with 2-methoxy-ethanol 2ethoxy ethanol and 2-butoxy ethanol at 308.15K",J.Pure.Appl.Ultrason.,23,26,2001.

[6] S.C.Bhatt,R.S.Rawat \& B.S.Semwal, "Acoustical investigation on some organic liquids",Acoust.Soc.Ind.,27,297,1999.

[7] H.K.Semwal, S.C.Bhatt and B.S.Semwal, "Acoustical study of binary liquid mixture of Acetic acid \& Isopropyl-sulphide",Pure Appl. Ultrason.25, pp.6$12,2003$.

[8] M. V. Rathnam, Kavita R. Bhanushali, Reema T. Sayed, and M. S.S. Kumar., "Acoustic,thermodynamics and transport properties of binary liquid mixtures of isopentyl acetate with aryl halides at $303.15 \mathrm{~K}$ and 313.15 K," Journal of Molecular Liquids, vol. 173, pp. 35- 41,2012.

[9] R. feng, Prog., Biochem Biophys, 2,8- 15,1980(in Chinese).

[10] Ana B. López, Alicia García-Abuín, Diego GómezDíaz, M. Dolores La Rubia and José M. Navaza., "Density, speed of sound, viscosity, refractive index and surface tension of N-methyl- 2- pyrrolidene + diethanolamine ( or triethanolamine) from $\mathrm{T}=(293.15$ to 323.15)K," Journal of Chemical Thermodynamics, vol. 61, pp. 1-6,2013.

[11] Ranjan Dey, Aditya Harshvardhan., "A Comparative study of Ultrasonic velocities of Binary and Multicomponent Liquid mixture at 298.15K.",Journal of Energy and Chemical Engineering, Vol 2 , Iss.I,pp1-7, Jan 2014.

[12] S.C Bhatt, Harikrishna Semwal, Vijendra Lingwal, Kuldeep Singh and B.S.Semwal., "Relaxation Time and Ultrasonic Attenuation in Some Binary and Ternary Liquid Systems" J.Acous.Soc. Ind., Vol. 28 No.1-4, pp 275-278,2000. 